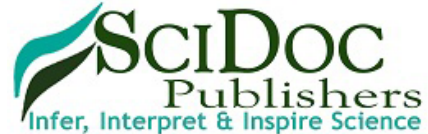

\section{Correlation between the Intelligence Quotient Of Children Aged 4-12 Years And Their Oral Hygiene Status}

Research Article

Ivan Obadiah ${ }^{1}$, Ganesh Jeevanandan ${ }^{2 *}$

${ }^{1}$ Saveetha Dental College and Hospitals, Saveetha Institute of Medical and Technical Sciences, Saveetha University, Chennai 600077, India.

${ }^{2}$ Reader, Department of Pediatric and Preventive Dentistry, Saveetha Dental College and Hospitals, Saveetha Institute of Medical and Technical Sciences, Saveetha University, Chennai 600077, India.

\title{
Abstract
}

In an individual, the intellectual level of the person defines the capacity to learn from experience, ability to sustain through new situations, cognitive development of the person and also the ability to alter the environment to the benefit of the person. The purpose of this study is to determine the correlation between the intelligence quotient of children aged 4 to 12 years and their oral hygiene status. This cross sectional study was conducted by measuring the $\mathrm{dmft}$ scores of the individuals and their IQ levels using an online test tool. A total of 75 participants were examined in the study and their oral hygiene status and IQ levels were evaluated and compared. There was no statistically significant association between the IQ levels of the participants and their $\mathrm{dmft}$ score.

\section{Introduction}

Intelligent quotient (IQ) was defined by Weschler as "an individual's ability to adapt and constructively solve problems in the environment" [1]. In an individual, the intellectual level of the person defines the capacity to learn from experience, ability to sustain through new situations, cognitive development of the person and also the ability to alter the environment to the benefit of the person. It shows the hereditary prospective and observational capacity of the individual [2]. The intellectual level of an individual exhibits both his/her own genetic potential and experiential inputs [3]. Alteration in the environment which leads to an unfavourable psychological development in the individual will eventually disturbs the cognitive development and coping ability of the person. Early childhood caries is a rapidly spreading infectious dental disease in children less than 5 years of age. There are various risk factors studied, which are responsible for the incidence of dental caries especially in children [4]. Intelligent quotient which is the measure of a person's intellectual level determines the cognitive ability of the individual in maintaining oral hygiene [5]. Poor oral hygiene maintenance eventually leads to dental caries and other soft tissue diseases like gingivitis etc. Correlations between intelligence quotient and dental health have been previously studied by few researches and the results are mostly contradictory [6]. Virk et al [3] studied orphanage children and concluded that an increase in IQ showed an increase in incidence of caries. In this modern era, children at an early stage in life have comparatively more intellectual abilities than previous generations. A high IQ score has to be associated with a healthy oral status and hence improving the intellectual development of an individual is essential in improving general and dental health $[1,3]$. The purpose of this study is to determine the correlation between the intelligence quotient of children aged 4 to 12 years and their oral hygiene status.

\section{Materials and Methods}

This cross sectional study was conducted between November 2020 to January 2021. The sample size calculation was done with $95 \%$ confidence interval, with the level of significance $\mathrm{p}<.057,8$. The adequate sample size was calculated as 73 samples.

\section{Inclusion criteria}

1. Children of age 4 to 12 years.

2. Individuals with one or more carious lesions

\section{*Corresponding Author:}

Ganesh Jeevanandan,

Reader, Department of Pediatric and Preventive Dentistry, Saveetha Dental College and Hospitals, Saveetha Institute of Medical and Technical Sciences, Saveetha University, Chen nai 600077 , India.

E-mail: helloganz@gmail.com

Received: June 11, 2021

Accepted: August 5, 2021

Published: August 14, 2021

Citation: Ivan Obadiah, Ganesh Jeevanandan. Correlation between the Intelligence Quotient Of Children Aged 4-12 Years And Their Oral Hygiene Status. Int J Dentistry Oral Sci. 2021;8(8):3695-3697. doi: http://dx.doi.org/10.19070/2377-8075-21000757

Copyright: Ganesh Jeevanandan ${ }^{\circ} 2021$. This is an open-access article distributed under the terms of the Creative Commons Attribution License, which permits unrestricted use, distribution and reproduction in any medium, provided the original author and source are credited. 


\section{Exclusion Criteria}

1. Individuals with special health care needs

2. Individuals who are uncooperative for the study

\section{Parameters}

1. dmft scores of the participants

2. Intelligence quotient scores of the participants

Tools used

1. $\mathrm{dmft}$ index

2. An online IQ test tool 9

Inference from the online test tool:

Statistical analysis was done to compare the association between the oral hygiene status and the intelligence level of the participants using the chi-square test in SPSS version 23.

\section{Results}

A total of 75 participants were examined in the study and their oral hygiene status and IQ levels were evaluated and compared. The age distribution throughout the participants was almost equally distributed (Graph 1). There was no statistically significant association between the IQ levels of the participants and their $\mathrm{dmft}$ score i.e $\mathrm{p}>0.05$ (Table 1 ). The most highly observed IQ levels among the participants were average and above average; and the most highly occurred dmft score was 4 (Graph 2).

\section{Discussion}

Psychology plays an important role in determining a person's behavior, but not many studies have been conducted in this regard.

\begin{tabular}{|c|c|}
\hline IQ score & Intelligence level \\
\hline$<70$ & Low \\
\hline $71-85$ & Below average \\
\hline $86-115$ & Average \\
\hline $116-130$ & Above average \\
\hline$>131$ & High \\
\hline
\end{tabular}

Graph 1. Distribution of age of the participants. The age distribution throughout the participants was almost equally distributed. Total number of 6 year old participants were higher comparatively.

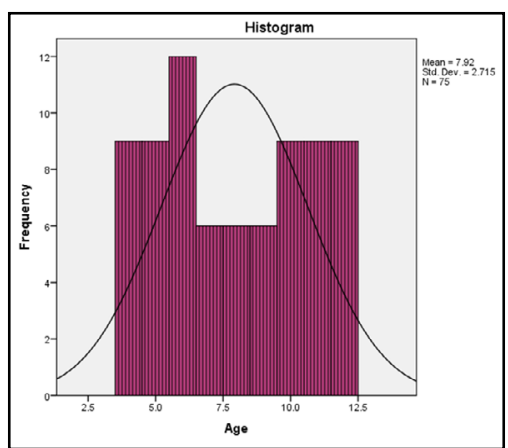

Graph 2. Associations between IQ levels of participants and their $\mathrm{dmft}$ scores.The most highly observed IQ levels among the participants were average and above average; and the most highly occurred dmft score was 4 .

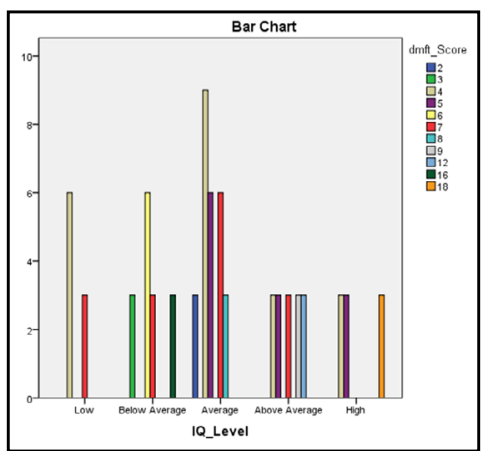

Table 1. Association between the IQ levels of participants and their $\mathrm{dmft}$ scores were statistically not significant ( $\mathrm{p}>0.05)$.

\begin{tabular}{|c|c|c|c|}
\hline & Value & df & Asymptotic significance (2-sided) \\
\hline Pearson Chi-square & 123.381 & 40 & 0.06 \\
\hline Likelihood Ratio & 109.511 & 40 & 0.058 \\
\hline Linear-by-Linear Association & 3.306 & 1 & 0.069 \\
\hline N of Valid cases & 75 & & \\
\hline
\end{tabular}


Psychology can be categorized under one or the other headings of intelligence, personality, temperament, maturity, curiosity, liking, study habits, adjustment functions, anxiety, developmental screening, creativity and others like frustration, general learning abilities, psychopathology, deprivation and helplessness [10]. Intelligence quotient of an individual depicts the level of cognitive development and it grades the adaptive ability of an individual to their environment. Right from birth an infant observes the immediate environment in which it grows and adapts to every single stimuli and nature of this world. Adapting to surrounding situations involves taking care of one self by following required daily routines like brushing the teeth, bathing and other such deeds. Developing skills for such daily activities requires a basic intelligence and adequate cognitive development. Singh [11] in his study among orphans, summed up the reason behind low performance on intelligence tests as non exposure to reading material, lack of interaction, prohibitive atmosphere, absence of care, and above all a feeling of being an orphan.

In this study, the IQ of the participants were measured using an online test tool which gave scores to each individual based on their performance in a 15 -item picture test questionnaire. The participants were mostly presented with color and shape matching questions and also few based on math solving questions and the questionnaires were age specific from 4 to 12 year old children. The participants were then graded according to their scores as low IQ, below average, average, above average and high IQ [12]. In this study, the most highly observed IQ levels were average and above average. These scores might not be very reliable as they were all in a format which the children hadn't come across before and might not have been taught before. And also, the anxiety of the children in the dental chair might have been a confounding factor in this study altering their response to the contest. The oral hygiene status of the participants in this study was determined by evaluation of the number of decayed teeth, missing teeth due to caries and also the teeth that were restored. When comparing these two and performing statistical analysis of their association, it was found that the IQ levels of the participants is not statistically associated with their oral hygiene status in this present study. But, however clinically participants who had a less dmft score scored more in the IQ test. Regarding the age of the participants, older children performed better in the IQ test than younger children [13]. This might be due to the better understanding of the environment and less dental anxiety [14]. In a similar study, prevalence of caries was less among the group with higher IQ than the group with lower IQ6. Institutionalized subnormal person with less IQ (20-49) had significantly reduced caries score than those with more IQ $(\geq 50)$, and when graphed from lowest to highest IQ, the caries score showed bell-shaped curve with persons of an average IQ having the highest caries score [15]. A study conducted by Shankar et al. [16] showed different relations such as increased dental caries with increased IQ levels. Virk et al [3] observed a lower score of IQ in socially handicapped orphan children. Navit et all concluded, prevalence of caries was maximum among those with border- line intelligence.

Limitations of this study was, the online test tool used was not a standardized universal IQ test tool. Dental caries incidence is multifactorial and there are many confounding factors which actually have more significance in causing it than that of an individual's intelligence.

\section{Conclusion}

1. Intelligence quotient of children aged 4 to 12 years is not associated with oral hygiene status of the children statistically.

2. Older children performed better in the IQ test than younger children.

3. More specific studies has to be conducted by eliminating the confounding factors.

\section{References}

[1]. Navit S, Malhotra G, Singh J, Naresh V, Anshul, Navit P. Interrelationship of intelligence quotient with caries and gingivitis. J Int Oral Health. 2014 Jul;6(4):56-62. Pubmed PMID: 25214734.

[2]. Solis-Riggioni A, Gallardo-Barquero C, Chavarria-Bolaños D. Prevalence and Severity of Dental Caries in Foster-Care Children and Adolescents. J Clin Pediatr Dent. 2018;42(4):269-272. Pubmed PMID: 29750620.

[3]. Virk P, Jain RL, Pathak A, Sharma U, Rajput JS. Inter-relationship of intelligence-quotient and self-concept with dental caries amongst socially handicapped orphan children. J Indian Soc Pedod Prev Dent. 2012 AprJun;30(2):127-32. Pubmed PMID: 22918097.

[4]. Muthu MS, Kumar S. Pediatric dentistry. Elsevier Health Sciences; 2019 May 10.

[5]. Tesini DA. An annotated review of the literature of dental caries and periodontal disease in mentally retarded individuals. Spec Care Dentist. 1981 Mar-Apr;1(2):75-87. Pubmed PMID: 6454266.

[6]. Bruckner RJ. Intelligence quotients and dental caries experience. J. Dent. Child.. 1952;19:64.

[7]. Prajapati B, Dunne M, Armstrong R. Sample size estimation and statistical power analyses. Optometry today. $2010 \mathrm{Jul}$ 16;16(7):10-8.

[8]. gpower.com, http://gpower.com (accessed 26 January 2021).

[9]. The most current IQ tests and real intelligence tests,IQ test for kids, http:// iqtestcenter.org (accessed 26 January 2021).

[10]. Satpathy M. Psychological tests developed for children in India: A review of recent trends in research, practice and application. Clinical Child Psychology, 1st ed. New Delhi: Kalpaz Publication. 2009:275-92.

[11]. Singh S. Guidance needs of destitute children:[a study of destitute homes in UP]. National Psychological Corporation; 1988.

[12]. Lynn R, Vanhanen T. IQ and global inequality. Augusta, GA: Washington Summit Publishers; 2006.

[13]. Ramos J. IQ Scale: IQ Charts By Age. Science Trends. Epub ahead of print 2018.

[14]. Sridhar S, Suprabha BS, Shenoy R, Shwetha KT, Rao A. Effect of a relaxation training exercise on behaviour, anxiety, and pain during buccal infiltration anaesthesia in children: Randomized clinical trial. Int J Paediatr Dent. 2019 Sep;29(5):596-602. Pubmed PMID: 30887592.

[15]. Steinberg AD, Zimmerman S. The Lincoln dental caries study. I. The incidence of dental caries in persons with various mental disorders. J Am Dent Assoc. 1967 Apr;74(5):1002-7. Pubmed PMID: 4381313.

[16]. Dhanu G, Havale R, Shrutha SP, Quazi N, Shafna TP, Ahemd A. Assessment of Intelligence Quotient using Raven's Coloured Progressive Matrices among school children of Hyderabad Karnataka region and its correlation with prevalence of dental caries. J Indian Soc Pedod Prev Dent. 2019 JanMar;37(1):25-30. Pubmed PMID: 30804304. 